\title{
Childhood Acute Myelomonocytic Leukemia
}

National Cancer Institute

\section{Source}

National Cancer Institute. Childhood Acute Myelomonocytic Leukemia. NCI Thesaurus.

Code C7970.

An acute myelomonocytic leukemia occurring in children. 